\title{
The CPS, Policy-Making and Assisted Dying: Towards a 'Freedom' Approach
}

\author{
Andrew Sanders*
}

In 2016 I evaluated the CPS after its first 30 years of existence. ${ }^{1}$ I did this through the lens of the 'freedom model'. ${ }^{2}$ This approach acknowledges that most people agree over the principal aims and values of criminal justice, at least at the level of rhetoric. Few people would argue against convicting the guilty, protecting the innocent, protecting everyone from arbitrary and oppressive treatment, treating victims with respect, and pursuing all this efficiently and proportionately.

The problem is that these values and interests often clash. The goals are not controversial, but their prioritisation often is. 'Freedom' can be a kind of common currency that allows us to weigh up, in any situation, how to prioritise. Criminal justice practices reduce the freedom of suspects, but some reduce it more than others. Compare, for example, out-of court disposals by the CPS with prosecutions: the former usually reduce freedom less than the latter. And some crimes - eg sexual offences - erode more freedom for victims and society at large than do others - eg driving offences. Convicting guilty careless drivers, then, while desirable, should not be as high a priority as convicting sexual offenders. It will be evident from these examples that current law and practice sometimes prioritise 'freedom', but frequently do not.

In an attempt to see what the 'freedom' model would look like concretely, I examined how far the CPS operationalised the three core criminal justice values that are integral to it: 'Justice', 'Democracy' and the 'Three Es' (efficiency, effectiveness and economy). Again, these are not controversial in themselves, but prioritisation between and within them is. ${ }^{3}$ I looked at how a range of policies and powers were formulated, interpreted and exercised. I

\footnotetext{
* University of Sussex. I would like to thank John Child, Anthony Duff, Penney Lewis and Trevor Ponman (a physicist!) for their comments on earlier drafts of this paper.

${ }^{1}$ A Sanders, 'The CPS - 30 Years On' Crim LR (2016) 82.

${ }^{2}$ Richard Young and I developed this in the $2^{\text {nd }}$ edition of our textbook. See A Sanders et al, Criminal Justice $\left(4^{\text {th }}\right.$ Ed, Oxford, OUP, 2010), Ch 1.

${ }^{3}$ For extensive discussion of these values in relation to the CJS in general see my 'Core Values, the Magistracy and the Auld Report' (2002) 29 Journal of Law and Society 324; and my 'Reconciling the Apparently Different Goals of Criminal Justice and Regulation: the Freedom Perspective' in H Quirk et al (eds), Regulation and Criminal Justice (Cambridge, CUP, 2010).
} 
concluded that CPS performance was improving, but still seriously deficient across all its work in relation to all three core values. This is due to its organisational culture, implicit and explicit policy choices, and structural position of police-dependence. One of the issues I examined briefly was assisted voluntary dying (AVD). Since space did not permit an extended treatment of this topic, this paper takes that opportunity. ${ }^{4}$ For my purposes AVD refers to assisted suicide (AS) and voluntary euthanasia (VE). We shall see that the CPS policy on AVD can be improved, but it will always fail the tests on 'Justice' and the ' 3 Es'. First we look at the policy on AVD, then at how it operationalises the three core values in turn, and then we will examine what would be needed to operationalise the 'freedom' model.

\section{The CPS Assisted Dying Policy}

\section{a) Assisted Suicide}

In Purdy, ${ }^{5}$ the applicant was suffering from MS. She wanted the CPS to promise that if her husband helped her to die when she asked him at some point in the future, he would not be prosecuted. The CPS refused, arguing that the Code for Crown Prosecutors gave guidance on this. Mrs Purdy correctly observed that the Code gave no indication of what would be likely to happen, for the 'public interest' factors are unprioritised. Which factor would be most important: the wishes of the 'victim' (Mrs Purdy) or the seriousness of the offence? If the latter, how seriously would assisted suicide be regarded? To counter this, by illustrating how it interpreted the Code in such cases, the CPS website summarised the case of Daniel James. ${ }^{6}$ This young man had been confined to a wheelchair following a sporting accident. His suicide was assisted by his parents, despite their initial reluctance, after he spent several years trying to adjust to his difficult circumstances. His parents were not prosecuted because they were motivated solely by compassion and Daniel had a voluntary, informed, clear and settled wish to die.

But one case does not make a policy. There was nothing in the Code to lead anyone to believe that the CPS would decide the Daniel James case in the way it did. There was no guarantee that the CPS, under a different DPP perhaps, would continue to decide cases like this in the same way in the future. So the House of Lords, as it then was, agreed with Mrs Purdy,

\footnotetext{
${ }^{4}$ In the interests of brevity, general CPS matters that are discussed in my ' 30 Years On' paper, such as the Code for Crown Prosecutors, will not be referenced in this paper (n1 above).

${ }^{5} R$ (on the application of Purdy) v Director of Public Prosecutions [2009] UKHL 45.

${ }^{6}$ https://www.cps.gov.uk/news/articles/death_by_suicide_of_daniel_james/
} 
ordering the DPP to issue guidelines setting out how this discretion would be used. He was asked to formulate a policy that would take account of a defendant's 'improper motive' ${ }^{7}$ but that would also seek to 'protect the right to make an autonomous choice'. ${ }^{8}$ The DPP speedily issued interim guidelines, based on existing practice ${ }^{9}$ as illustrated by the Daniel James case. There was a brief consultation after which the final version was published. ${ }^{10}$

The main elements of the final version identify prosecution as more likely when:

- the victim was under 18 years of age;

- the victim had not reached, or was not capable of reaching, a voluntary, clear, settled and informed decision to commit suicide and/or was subject to pressure from D or others;

- the victim had not clearly and unequivocally communicated his or her decision to commit suicide to the suspect;

- the victim did not seek the assistance of the suspect personally or on his or her own initiative;

- the suspect was not wholly motivated by compassion;

- the suspect had a history of violence or abuse against the victim;

- the victim was physically able to undertake the act that constituted the assistance him or herself;

- the suspect was unknown to the victim and assisted the victim by providing specific information via, for example, a website or publication;

- the suspect assisted more than one victim who were not known to each other;

- the suspect was acting in his or her capacity as eg a medical doctor, nurse, other healthcare professional, a professional carer;

- the actions of the suspect were of substantial assistance;

- the suspect had not sought to dissuade the victim and/or did not act reluctantly.

\footnotetext{
${ }^{7}$ Purdy (n 6) (Lord Hope [63]).

${ }^{8}$ Baroness Hale at [65]. The ratio of the case is therefore arguable. However, the ECtHR decided in Pretty [2002] 35 EHRR 1 that a blanket prohibition on assisted suicide engaged Art 8 (1), although under Art 8 (2) this was permissible as long as some discretion was exercised in enforcing it. Art 8 considerations (giving effect to autonomy) should therefore have been be paramount.

${ }^{9}$ Which was, in particular, to give 'safe passage' for those assisting the trip to Dignitas (the Swiss life-ending clinic) of 115 people who were known to have done this until that time, eight were referred to the DPP but none prosecuted: Purdy [30].

${ }_{10}$ For the consultation see http://www.cps.gov.uk/consultations/as_responses.html. The final policy is at http://www.cps.gov.uk/publications/prosecution/assisted_suicide_policy.html. Updated October 2014. Last visited, $8^{\text {th }}$ August 2017.
} 
We know from the fact that AS is rarely prosecuted (see Part IV below) that the guidelines pointing against prosecution are given great weight in practice. People are not prosecuted when they are judged (by police and CPS) to have helped people who express a voluntary, informed, clear and settled wish to die. The guidelines seek to discourage people from helping others to die when they have something to gain from the death. But whether this policy succeeds in both protecting the vulnerable and preserving the autonomy of those who wish to die is another matter.

The DPP could have formulated a policy that simply said he would not prosecute if the 'victim' had a voluntary, informed, clear and settled wish to die. Instead, the focus on the motivation and role of the perpetrator restricts assisted suicide more than Purdy required and in ways that do not relate to the decision's interpretation of Art 8 ECHR (the protection of autonomous choices to die). ${ }^{11}$ The DPP's policy attempts to compromise between 'autonomy' and 'sanctity of human life' positions.

\section{b) Voluntary Euthanasia}

The DPP could have included VE within the AVD policy, but chose not to do so. This may reflect the commonly held view that VE and AS are fundamentally different. Montgomery, for example, views the elements of the policy that stress the virtue of minimal assistance as positive as, in his view, 'this maintains the distinction between suicide and homicide.' 12 But Montgomery makes no distinction between voluntary and involuntary homicide.

We can categorise people who seek VE as follows:

a) those who are physically incapable of taking the final step;

b) those who try and fail to take the final step themselves;

c) those who do not wish to take the final step themselves.

\footnotetext{
${ }^{11}$ J Rogers, 'Prosecutorial Policies, Prosecutorial Systems and the Purdy Litigation' (2010) Crim LR 543. Making compassion a factor has been criticised on various grounds. For example, as motive is not generally part of the substantive law, taking account of compassion (a motive) is said to change 'the law' by the 'back door' (C O'Sullivan, 'Mens Rea, Motive and Assisted Suicide: Does the DPP'S Policy Go Too far?' (2015) 35 Legal Studies 96). The argument is hard to follow, since all guidelines change 'the law' (if we accept this positivistic idea of 'law') by the back door. The fault, if there is one, is therefore that of the court in Purdy - which required the DPP to issue guidelines of some kind and which, in some judgements, focussed on motive - not that of the DPP. As Lewis observes, different judgements in Purdy had different emphases (P Lewis, 'Informal Legal Change on Assisted Suicide: The Policy for Prosecutors’ (2011) 31 Legal Studies 119). For a philosophical discussion focussing on the 'compassion' element see A Duff, 'Criminal Responsibility and the Emotions: If Fear and Anger Can Exculpate, Why Not Compassion?’ Inquiry (2015) 58, 189.

12 J Montgomery, 'Guarding the gates of St Peter' (2011) 31 Legal Studies 644 @ p661.
} 
But reality is messy. Each category could include those who would have been able to take the final step with assistance but did not because of the constraints of the AS laws (eg, fear that their assister(s) would be prosecuted or that they would not be successful), or who perhaps tried and were unsuccessful, and who waited until they were desperate to die but were no longer confident they could take the final step themselves.

Nicklinson concerned a middle aged man with 'locked-in' syndrome following a devastating stroke. ${ }^{13}$ After trying to make a satisfying life for a considerable time with this condition he decided he no longer wished to live. He could make his wishes known clearly by using a computer linked to his eye movements, but this was the only movement of which he was capable. He was therefore in category (a). For such people there are currently just 3 solutions:

1. Travel to Dignitas in Switzerland, which is very difficult with the apparatus most people in category (a) need to live;

2. Self-starvation; ${ }^{14}$

3. Continuing to suffer, which for the appellants in Nicklinson was "undignified, distressing and intolerable." 15

Despite this, the appellants (almost inevitably) failed in their claims. One argument concerned Art 8. But since the Art 8 arguments in relation to AS failed (because of the 'margin of appreciation' ie the leeway given by the ECHR to domestic jurisdictions to order their criminal justice systems as best fits domestic tradition and culture), the Court of Appeal considered that the same would have to be true of the more serious offence of murder even when it takes the form of VE. ${ }^{16}$

A more substantial argument was 'necessity', though as 'necessity' is excluded in cases of murder the appellants were necessarily going to struggle with this too. An analogy was drawn with the 'conjoined twins' case, which allowed doctors to separate twins knowing this would kill one of them. ${ }^{17}$ But the crucial difference between the two cases is that in the

\footnotetext{
${ }^{13}$ Nicklinson [2013] HRLR 36.

${ }^{14}$ The solution adopted by Nicklinson after he lost his case in the Divisional Court. His case was appealed, to the Court of Appeal and then the Supreme Court, on his behalf.

${ }^{15}$ Lord Neuberger [470].

${ }^{16}$ Nicklinson [2012] EWHC 2381 (Admin). For critical analyses see C Draghici, 'The blanket ban on assisted suicide: between moral paternalism and utilitarian justice' (2015) European Human Rights Law Review 3, 286; J Adenitire, 'A conscience-based human right to be "doctor death' (2016) Public Law 613. 17 Re A (Children) (Conjoined Twins: Surgical Separation) [2001] 2 W.L.R. 480.
} 
'conjoined twins' case both would have died without intervention, while in Nicklinson all the appellants could live indefinitely. More fundamentally, if there is no defence of necessity for AS, how can there be one for the more serious offence of VE? ${ }^{18}$ And how could there be a defence of necessity for AS when section 2 of the Suicide Act criminalises it? ${ }^{19}$ Herring attempts to answer this as follows. If the person seeking VE cannot kill him/herself, that person's Art 8 rights can only be realised by allowing a person of choice to kill him/her. ${ }^{20}$ However, everyone, no matter how disabled, can kill themselves by starving themselves to death. This is precisely what Tony Nicklinson and others ${ }^{21}$ did. This gross inhumanity, comparable with torture (violation of Art 3), provides one reason for changing the law. But it is always an option. Herring might respond that it is 'necessary' to allow an option that does not violate Art 3. But exactly the same argument could apply for many people seeking assistance in suicide, as many of them, too, have no humane way to die except with the help of others.

Whatever the precise arguments, it is clear that there will be no judicial development of a VE policy anytime soon, even for people in category (a). So the CPS policy on AS should logically include VE for people in Tony Nicklinson's situation at the very least. But all the policy says is:

If the course of conduct goes beyond encouraging or assisting suicide, for example, because the suspect goes on to take or attempt to take the life of the victim, the public interest factors tending in favour of or against prosecution may have to be evaluated differently in the light of the overall criminal conduct. [48]

\footnotetext{
${ }^{18}$ Nicklinson [2013] HRLR 36 [66]. The necessity argument was probably run because this is how VE developed in the Netherlands (S Michalowski: 'Relying on common law defences to legalise assisted dying: problems and possibilities' Medical Law Review (2013) 21, 337). A 'necessity' argument cannot, of course, co-exist with an autonomy-based argument for voluntary euthanasia: one cannot argue for choice if one is also arguing that there is only one solution. For a more general discussion reaching similar conclusions, see F Stark, 'Necessity and Nicklinson' (2013) Crim LR 949.

${ }^{19}$ Unless, as with most offences, the defence were to apply in only some circumstances. But it is difficult to envisage what circumstances would make a difference to whether such a defence would apply to AS or VE.

${ }^{20} \mathrm{~J}$ Herring, 'Escaping the shackles of law at the end of life: $R$ (Nicklinson) v Ministry of Justice' Medical Law Review (2013) 21, 487-492. This is a version of the 'necessity' defence urged on (but not accepted by) the courts by S Gardner, 'Direct Action and the defence of necessity' [2005] Crim LR 371.

${ }^{21}$ Such as Jean Davies, an 86-year-old who was suffering from several painful and distressing health problems: http://www.theguardian.com/society/2014/oct/19/right-to-die-campaigner-starved-herself-jean-davies. Both she and Tony Nicklinson took 2+ weeks to die, though it seems that infections, brought on by their starved conditions, were the technical causes of death.
} 
Turning to category (b), Keating and Bridgeman give several examples. ${ }^{22}$ Vanessa Cook suffered from MS and depression and unsuccessfully tried three times to kill herself before taking an overdose and asking her husband not to call emergency services before she was dead. Her husband ensured she died by suffocating her. Sarah Lawson attempted suicide three times in the week before a final attempt was reinforced, again, by suffocation, this time by her father. The courts in these cases generally convict of manslaughter on grounds of diminished responsibility (not murder) and award non-custodial sentences, thus demonstrating the absence of doubt about the compassionate and consensual basis of the death. But why convict at all in that case? Moreover, not all defendants in these circumstances are so lucky: when Frank Lund ensured his serially-suicidal wife actually died, as she requested, he was convicted of murder and sentenced to 'life'. ${ }^{23}$ In similar circumstances, George Webb smothered his extremely ailing wife when her suicide attempt (which he reluctantly assisted) was failing, as she had asked him to do. He pleaded guilty to manslaughter on the grounds of diminished responsibility. This man of 73, with psychiatric problems and suffering the double anguish of his wife's death at his own hands, still served six months imprisonment before his sentence was reduced on appeal. ${ }^{24}$ So he was luckier than Frank Lund, but still suffered abominably at the hands of our justice system for carrying out a last act of love at the request of the 'victim'. ${ }^{25}$

It is clear that the CPS policy remains problematic. But to fully understand this, and before we can begin to plot a way forward, we need to review it using the 'core values' within the freedom approach.

\section{First Core Value: Democracy}

A consultation process is only an exercise in democracy if consultee responses are taken into account in a principled way. This can only be done if the principles underlying the policy to be consulted on are articulated. No principles were articulated when the CPS consulted on its draft

\footnotetext{
${ }^{22} \mathrm{H}$ Keating and J Bridgeman, 'Compassionate killings: the case for a partial defence' (2012) 75 MLR 697.

${ }^{23}$ R Ford, 'Life may mean just 3 years for “mercy killing” husband' The Times 25 May 2007.

${ }^{24}$ Webb (2011) EWCA Crim 152.

${ }^{25}$ Changes to the law on diminished responsibility (Coroners and Justice Act) now make this route to manslaughter less likely to be available in such cases: M Gibson, 'Pragmatism Preserved? The Challenges of Accommodating Mercy Killers in the Reformed Diminished Responsibility Plea' (2017) 81 Jo Criminal Law 177.
} 
policy. There is insufficient space to analyse the CPS response to all the issues raised in the consultation, but here are the most important examples.

i) The interim policy included several suspect-oriented factors (eg, whether the suspect had an entirely compassionate, as compared to a financial or malicious, motive). A majority of respondents agreed with these factors, and they found their way into the final policy. But only a minority of respondents agreed with the victim-oriented mitigating factor that found its way into the final policy (that the 'victim' had a voluntary, informed, clear and settled wish to die).

ii) The interim policy 'weighted' some factors as more important than others. Over $80 \%$ of respondents agreed with 'weighting' in relation to 7 of the 8 pro-prosecution factors (the 7 that eventually found their way into the final policy). But the decision was taken not to continue this weighting into the final policy on the bizarre ground that not weighting 'makes the final policy clearer and more accessible' even though 'the particular facts of the case may mean that one factor alone may outweigh a number of other factors which tend in the opposite direction. ${ }^{26}$ This means that although the policy allows for one factor to be weighted more heavily than another, it is claimed that the policy will be clearer and more accessible if no indication is given of which factors will be so weighted, to what extent, and in what circumstances. But this is not self-evident. Nor is there any explanation of how clarity and accessibility were weighed against public approval. Would the same decision have been taken if $99 \%$ of respondents had approved of the weighting?

iii) The consultation asked what other public interest factors might have been included in favour of, or against, prosecution. A few suggestions favouring prosecution were adopted in the final policy. But the suggestion that written documentation signifying a wish to die (such as a living will) be a factor against prosecution was rejected. This was on the ground that it was not for the CPS to recognise such a step if Parliament did not. Yet this whole policy takes a step away from a clear Parliamentary decision (ie, retaining the blanket criminalisation of assisted suicide in the Suicide Act, as amended as recently as 2009!) ${ }^{27}$

It is therefore impossible to identify a rationale for the CPS following the lead of respondents at some times but not at other times. Even when the principle adopted is clear such as how great a role the suspect had - this principle might equally have been rejected. Two senior members of the CPS comment that 'Of course, the public's view, whilst persuasive,

\footnotetext{
${ }^{26}$ CPS, Public Consultation exercise (Feb 2010) [4.7 and 4.8].

${ }^{27}$ Section 2 was amended by s59 and Schedule 12 of the Coroners and Justice Act 2009.
} 
cannot be determinative of any particular issue ... without reference to other considerations. ${ }^{28}$ But they do not tell us what those other considerations were, or how they were balanced against the views of the public. Did the CPS look at how strongly expressed a view was? How widely held? How logical? How consistent with other principles? They argue that the consultation process was nonetheless vindicated because 'The public gave its views and the Director has reflected the vast majority of them. ${ }^{29}$ This quantitative approach is one of several ways in which the consultation failed to comply with the governmental consultation criteria operating at that time. ${ }^{30}$ And, while it is true that the final policy does in general reflect the majority of views, we have seen that it is not true in several respects, and that no convincing explanation was given about why some views were accepted and others not.

Thus a 2-stage process was adopted, in which the second stage did not follow logically from the first. The DPP seems to have acted on the consultation responses that he liked, and not on others, for no clear reasons and with no guiding principle. The final policy is therefore as muddled as was the interim policy. We shall see that it is also cruel and restrictive of autonomy. This is because the consultation did not identify the fundamental principle that the policy was supposed to safeguard. If that principle was the protection of autonomy we would expect the policy to have two limbs: allowing 'perpetrators' to do whatever victims wish them to do, whether this involves a major part in the suicide or a minor part, whether done reluctantly or as part of a Dignitas-style organisation; and guarding against pressure on victims to commit suicide. ${ }^{31}$ Those who have something to gain from suicide are usually family. So the policy's endorsement of family assistance and discouragement of professional assistance is perverse. Where was the evidence base for this choice? In the Netherlands assisted suicide requires medical endorsement. ${ }^{32}$ Is it plausible that what works best for people contemplating suicide is completely different in two ostensibly similar western democracies?

\footnotetext{
${ }^{28} \mathrm{R}$ Daw and A Solomon, 'Assisted Suicide and Identifying the Public Interest in the Decision to Prosecute' (2010) Crim LR 737, 743.

${ }^{29}$ ibid p748.

${ }^{30} \mathrm{P}$ Lewis, $\mathrm{n} 11$ (whose critique of the way the consultation was conducted is of huge value). The 2016 criteria supra are silent on this issue.

${ }^{31}$ This is a great over-simplification of the nuances and controversies around the concept of autonomy. See, for example, S McLean, Autonomy, Consent and the Law (Routledge, 2010); C Foster, 'Autonomy in the medicolegal courtroom: A principle fit for purpose?' Medical Law Review (2014) 22, 48. There are many critiques of, and warnings against, autonomy as an over-riding legal principle in general, such as M Shehan, 'Deflating Autonomy' in M Häyry and T Takala (eds), Scratching the Surface of Bioethics (Rodopi, 2003); C Foster, Choosing Life, Choosing Death: The Tyranny of Autonomy in Medical Ethics and Law (Oxford, Hart, 2009,) esp ch 11. See further discussion in section $\mathrm{V}$.

${ }^{32}$ For examples of the many discussions of the Netherlands see Lewis, n 11; E Delbeke, 'The Way Assisted Suicide Is Legalised: Balancing a Medical Framework against a Demedicalised Model' (2011) 18 EJ Health Law 149.
} 
If the CPS had started from these principles it would logically have had to consider whether VE should be included in its policy. It would then have had to have consulted accordingly. For the essence of VE is allowing 'perpetrators' to do whatever victims wish them to do, whether this involves a major part in a death or a minor part,

Further what kind of public consultation should have been conducted? Unlike theft or drink-driving, laws that regulate AVD do not directly affect 'the public' as a whole. They mainly impact on people who suffer terminal, disabling or serious chronic ailments and those close to them. Yet no consultation was done with these particular groups of people, or indeed with the medical profession. Giving the general public $a$ voice is appropriate. But giving the general public the only voice is surely irrational. It is also contrary to current government guidelines: 'Consider the full range of people, business and voluntary bodies affected by the policy, and whether representative groups exist. Consider targeting specific groups if appropriate. ${ }^{33}$ And the Northern Ireland government website, for example, states that 'consultation is ... about making policies more effective by listening and taking onboard the views of the public and interested groups. 34

If consultation exercises had been done with different groups of people their responses could have been compared. Even so, comparison cannot be done in a vacuum. Without explicit principles to underpin whatever would become the final policy, comparison would be worthless.

\section{Second Core Value: Justice}

'Justice' can have many meanings, and there is no space in this paper to explore them all. I first look at whether, on balance, this policy leaves 'victims' better or worse off than a more permissive policy would leave them. I then examine the way in which 'perpetrators' are differentiated.

\section{Justice for Victims}

Since 'victims of crime should be at the heart of the [criminal justice] system', ${ }^{35}$ the CPS claims that 'Championing justice and defending the rights of victims, fairly, firmly and effectively is

\footnotetext{
${ }^{33}$ https://www.gov.uk/government/publications/consultation-principles-guidance (2016). Visited 7 August 2017.

${ }^{34}$ https://www.nidirect.gov.uk/articles/public-consultations (my emphasis).

35 Justice for All (Cm 5563, 2002), Forward.
} 
at the heart of all we do. ${ }^{36}$ The effect of the final policy is that AS perpetrators are at risk of prosecution when they provide assistance in the following ways.

Provide specialist advice: Anyone who offers organised assistance is likely to be prosecuted, as are health care professionals with a duty of care to the 'victim'. ${ }^{37}$ Thus the policy is 'designed to ensure that assistance in suicide remains an amateur activity carried out by inexperienced individuals without the assistance of professionals. ${ }^{38}$ The result is botched suicides: failed attempts and deaths that are more painful and distressing than they need to be, such as the examples given in Part I(b) above. One of the most distressing examples is the first prosecution for AS carried out between the publication of the guidelines and the decision in Nicklinson. The perpetrator provided petrol and a lighter to a vulnerable man known to have suicidal intent, and who subsequently suffered severe burns as a result. ${ }^{39}$ Defenders of the policy may see this case as vindication of its restrictiveness, enabling prosecution of the irresponsible perpetrator. In reality it serves to condemn that policy, for if the victim had been able to secure better advice and assistance it is unlikely that he would have suffered so horrifically.

Facilitate suicide in an organised way in the UK: Many UK citizens travel to Switzerland to die at Dignitas, generally assisted by friends and/or family who are never prosecuted. ${ }^{40}$ But it is likely that anyone organising a Dignitas-type process in the UK would be prosecuted. ${ }^{41}$ For example, a tip-off about a 'euthanasia kit' prompted police to raid and (it is reported) break down the door of an 82-year old wanting to end her life, causing her to delay - but not abandon - her suicide in $2016 .{ }^{42}$ This is obviously irrational. It is also cruel and unjust to most victims:

\footnotetext{
${ }^{36}$ http://www.cps.gov.uk/victims_witnesses/index.html.

${ }^{37}$ Para 43, Factors 5, 6, 11, 12.

${ }^{38}$ Quoted by Patricia Hewitt HoC Hansard 10 March 2010, col 403 from P Lewis, 'Out of Focus' (2010) Solicitors $J$; 154(9):10-11, 11. For a lengthier and highly persuasive discussion see Lewis, n 11. This remains true even though health care professionals giving advice and assistance when not acting in their professional capacities are now (following an amendment to the Policy) treated like anyone else acting for compassionate reasons. See Para 43, Factor 14.

39 http://www.cps.gov.uk/news/latest_news/kevin_howe convicted_of_assisted attempted_suicide/.

40 This is consistent with Para 45 Factors 1 and 2 if, as the CPS sees it, helping the 'victim' to travel to Dignitas is regarded as minor assistance. This seems to be an a priori principle. It cannot be reconciled with any kind of reality in relation to people who need assistance to travel to Switzerland. Note that neither Dignitas nor Dignitasstyle process and institutions are specifically mentioned in the CPS Policy, though under Para 43, Factor 16, prosecution is 'more likely to be required if ... the suspect was [in] ... an organisation or group, a purpose of which is to provide a physical environment ... in which to allow another to commit suicide.'

${ }^{41}$ Factor 16.

${ }^{42}$ Guardian 22/4/2016.
} 
- It compounds the suffering of people who wish to die, and that of their friends and family, by requiring travel to a foreign country away from the comfort of one's home and loved ones;

- Travel to Switzerland will often be painful and difficult, particularly for people whose painful conditions are a precipitating factor in leading them to decide to end their life;

- $\quad$ It costs around $£ 8000$ to use Dignitas. ${ }^{43}$ Travel costs, for the 'victim' and friends/family are extra. This is unaffordable for many people.

This part of the policy also erodes the second limb of the autonomy principle identified in Part II. It puts pressure on some victims to die earlier than they otherwise would. People suffering degenerative illnesses, in particular, would be able to delay their death longer if they only had to travel to a 'UK-dignitas' than if they have to make the difficult journey to Switzerland. And who knows how many people, knowing that a 'UK-dignitas' would be available as a safety net, would not in fact take, or ask for help in taking, the final step? The implicit push to travel to Switzerland actually encourages AS.

Provide substantial assistance: ${ }^{44}$ Three people were arrested in Loder's case. It was decided there was insufficient evidence against one, and that it was not in public interest to prosecute the other two. One had only contributed to the deceased's 'preparations' while the other had only had two phone conversations with her. ${ }^{45}$ This sends a clear signal to 'perpetrators': do as little as possible to help victims see their final wishes fulfilled. This contributes to the number of botched suicides referred to above, pushes sufferers to Switzerland, and consigns many 'victims' to loneliness in their final and most distressing stages of life. If 'victims' want others to have major roles in their deaths, to make the final steps easier, why deny them their wishes? The logic of this argument then extends, of course, to VE: if the major role that someone wants another to have is to actually take that person's life, there is no reason to deny it. A common objection to AS is precisely this: that it is a 'slippery slope' to VE and worse. 'Slippery slope' arguments have been comprehensively demolished by Smith and are briefly addressed later. ${ }^{46}$

\footnotetext{
${ }^{43}$ N Richards, 'Assisted Suicide as a Remedy for Suffering? The End-of-Life Preferences of British "Suicide Tourists"' Medical Anthropology (2017) 36, 348.

${ }^{44}$ Para 43, Factor 10, and Para 45, Factor 3.

${ }^{45}$ http://www.cps.gov.uk/news/latest_news/cps_statement_on_decision_in relation_to_doctor_elisabeth_wilson/ See Guardian, 16 August 2010.

${ }^{46} \mathrm{~S}$ Smith, 'Evidence for the practical slippery slope in the debate on physician-assisted suicide and euthanasia' (2005) Medical Law Review, 17.
} 


\section{Justice for Perpetrators}

Prosecution decisions should differentiate suspects who facilitate the autonomy of victims (by helping them carry out their freely made wishes) from those who subvert it (by persuading them to attempt suicide). Is that what this policy does?

We have seen that it makes the provision of specialist advice hard to secure, leading to botched suicides. But surely detached medical professionals are less likely to persuade people to take their own lives than families and carers who may gain from these deaths. Further, in many suicide attempts made without specialist assistance the assister - unbearably distressed at seeing their loved one suffer the threefold hardship of their original problem, the decision to end their life and the failure to secure this objective - ends up being the actual killer. As we have seen, this 'amateur' VE is technically homicide and is prosecuted more frequently than AS.

We have also seen that the amount of assistance influences prosecution decisions. It is not obvious that taking a greater role indicates more undermining of victim autonomy - more culpability - than where suspects avoid this responsibility.

Take the part of the policy that makes prosecutions more likely when suspects do not seek to dissuade victims and/or do not act reluctantly. ${ }^{47}$ This is a random value judgement about culpability. Many suspects who are reluctant to help 'victims' would presumably consider the suicide of those 'victims' to be irrational (for if a proposed suicide were rational why would a 'perpetrator' be reluctant to help a loved one?). ${ }^{48}$ But if victims and/or their suicides are considered irrational, surely helping those victims to die would be wrong, as treatment or persuasion might enable the victim to see sense. Yet people who reluctantly assist suicide are less likely to be prosecuted than those who do so with understanding and respect for their loved one's wishes.

Finally, the number of factors in the policy requires extensive police investigation to enable CPS to make a decision in accordance with it. Even though most suspects are not prosecuted, many are arrested, and in all cases investigations are intrusive. This all adds to the distress these loved ones have to endure - losses to their 'freedom' ${ }^{49}$ in other words.

\footnotetext{
${ }^{47}$ Para 45 , Factor 4 and 5.

${ }^{48} \mathrm{I}$ am interpreting 'reluctance' as having reservation about helping, as distinct from sadness at the outcome; sadness is normal, and anyone who does not feel sad when contemplating the death of a loved one is indeed worthy of suspicion if $\mathrm{s} /$ he helped that person to die.

${ }^{49}$ In the way we use it in Criminal Justice, $\mathrm{n} 3$.
} 


\section{Third Core Value: The Three 'Es'}

Every assisted suicide that is reported to the police is investigated by them, who then send a file to the CPS. Suspects are interviewed under caution and frequently following arrest. Yet hardly any are prosecuted:

Table 1: Assisted Suicide Referred to the CPS by Police, April 2009-July 201750

\begin{tabular}{|l|l|}
\hline Withdrawn by police & 28 \\
\hline Not proceeded with by CPS & 85 \\
\hline Ongoing & 8 \\
\hline Referred for prosecution for other serious offences & 7 \\
\hline Prosecuted & 2 \\
\hline Not known (Included as CPS figures do not add up) & 6 \\
\hline Total Referred & 136 \\
\hline
\end{tabular}

Nine possible prosecutions out of 136 cases is such a low percentage that the expenditure of resources - efficiency and economy - has to be a concern. But this is an inevitable consequence of post-death assessment.

The effectiveness of the policy (the third ' $E$ ') is also questionable. First, the fulfilment of victims' wishes is hampered by the co-focus on 'the motivation of the suspect'. Botched and repeated suicide attempts are just the visible examples of this. There are doubtless many others who wish to end their lives but who do not; they continue to suffer because they have no access to expertise or help, or because they fear a lonely or botched attempt.

Second, the proxies for assessing autonomy are ill-chosen. The policy rightly seeks to protect victims from those who might pressure them into suicide. But as we have seen, those most likely to exert such pressure are those with most to gain from a person's suicide (such as family and close friends), and those least likely to exert such pressure are those with little or nothing to gain (such as professionals). Yet the policy facilitates AS by family and friends, and discourages AS by professionals.

Third, we know that prohibiting activities that are desired by all parties to them does little to reduce them. What happens to such activities - such as drug taking, abortion, prostitution, gambling, American 1920s Prohibition - is that they go underground. The

${ }^{50}$ http://www.cps.gov.uk/publications/prosecution/assisted_suicide.html. 
activities are then more difficult to quantify and control. The 'dark figure' of both AS and euthanasia (voluntary and not voluntary), while impossible to estimate, is undoubtedly higher than if it were not a) criminal; and b) restricted more than an autonomy-based policy would be.

Medical euthanasia, in particular, is rife. This is often done under the guise of 'palliative care' and 'deep sedation'. It is usually justified, when called to account, by the doctrine of 'double effect', which was made part of English law in Adams. ${ }^{51}$ This holds that where a medical intervention is done primarily to alleviate pain and suffering, there is no homicide even if the person administering it knows that death is a virtually certain consequence. Opponents of AS, as well as proponents, should be equally worried. Unlike 'regular' AS or VE, there is no automatic police investigation - in fact, there is usually no investigation at all, even when doctors announce that life-ending was their main motive. ${ }^{52}$ But nor is there any system of recording the patients' wishes. We have to trust the medics that this was what the patient wanted and/or that death was imminent anyway.

In a survey of end-of -life decisions, medical practitioners said that over $17 \%$ of deaths involved 'double effect' and over 16\% involved continuous deep sedation (CDS). ${ }^{53}$ Mason and Laurie suggest that '... terminal sedation ... [is] ... likely to represent an instance of euthanasia hiding under emollient terminology. ${ }^{54}$ Huxtable gives numerous examples where 'double effect' is abused - for example, a junior doctor claiming that the lives of elderly terminal patients are sometimes shortened to manage bed shortages. Ironically, it is now thought that Dr Adams was actually a mass murderer akin to Harold Shipman. ${ }^{55}$ And what are we to make of Howard Martin GP, who admitted hastening the death of dozens of his patients, some - but not all - at their request? He was tried for murder, acquitted, and then struck off. ${ }^{56}$ While mass murderers are hopefully few and far between, mass murder probably is not. Although estimating the 'dark figure' is impossible, is seems that it is far more extensive than most people - including, crucially, respondents to the CPS consultation - imagine. In 1999 it was estimated that up to 100,000 patients a year are quietly helped to die in the UK. ${ }^{57}$ In an Australian survey

\footnotetext{
51 [1957] Crim LR 773. See discussion in, for example, J Montgomery, n 13; and in D Price, 'Euthanasia, Pain Relief and Double Effect' (1997) Legal Studies 17, 323.

${ }^{52}$ R Huxtable, 'Get out of jail free? The doctrine of double effect in English law' Palliative Medicine (2004) 18, 62.

${ }^{53} \mathrm{C}$ Seale, 'End of life decisions in the UK involving medical practitioners' 23 (2009) Palliative Medicine 198.

54 J Mason and T Laurie, Mason and McCall Smith's Law and Medical Ethics (8th Ed, OUP, 2000) 580.

${ }^{55}$ R Huxtable, 'Get out of jail free? The doctrine of double effect in English law' Palliative Medicine (2004) 18, 62. On Shipman, see Griffiths and Sanders ed (2013) [Ref]. A Sanders \& D Griffiths (eds), Medicine, Crime and Society (CUP, 2013)

56 http://www.theguardian.com/society/2010/jun/19/howard-martin-doctor-euthanasia.

${ }^{57}$ R H Tur, 'Just how unlawful is "euthanasia"?' (2002) Journal of Applied Philosophy, 219-232.
} 
of 683 surgeons, over one-third (247) stated that, when administering drugs to alleviate suffering, they administered more than necessary for this purpose but with the intention of hastening death. Moreover, it may be that the main difference between the 247 and the rest is their self-evaluation of their mental state. ${ }^{58}$ Magnusson also estimates that 'a significant proportion of the medical profession has participated, illegally, in assisted death' in Australia. ${ }^{59}$ Similarly the 1996 BBC Scotland survey on medical AS showed that $12 \%$ of health care professionals personally knew another professional who had hastened death, while $4 \%$ said they did this themselves. ${ }^{60}$ In yet another example, a doctor in Hampshire was found guilty of serious professional misconduct by prescribing opiates and sedatives in 'excessive, inappropriate and potentially hazardous’ ways. This is now the subject of a $£ 13 \mathrm{~m}$ inquiry into hundreds of deaths to which she may have contributed. ${ }^{61}$

Most non-voluntary medical euthanasia is mercy-killing, but there are occasional bounty-hunters and pathological killers. Only rarely is it identified or investigated, and even more rarely prosecuted. The rare example of Howard Martin being prosecuted turned on its extreme facts; and also perhaps on him acting alone. ${ }^{62}$ His acquittal will have done nothing to encourage future prosecutions or deter medical killing without consent.

Thus while no doubt many, probably most, of people who die as a consequence of 'double-effect' do wish to die (or would, if they could express an opinion), there will doubtless be some who do not. The policy therefore lacks effectiveness because it fails to protect many of these people, failing to give effect to the second limb of the autonomy principle identified in Part II. As Orentlichter says '... terminal sedation is a method of death that is ethically inferior to assisted suicide. ${ }^{63}$ Moreover, 'double-effect' is physician-oriented, not patientoriented: what matters is what the physician wanted/intended, not what the patient wants/intends. ${ }^{64}$ This runs directly counter to the victim-centred criminal justice policy

\footnotetext{
${ }^{58} \mathrm{C}$ Douglas et al, 'The intention to hasten death: a survey of attitudes and practices of surgeons in Australia' (2001) 175 Medical Journal of Australia 511, quoted in Ost (2005) Crim LR 355.

59 R Magnusson, Angels of Death: Exploring the euthanasia underground (Melbourne, Melb UP, 2002$) 40$.

${ }^{60}$ Daruwala, review of J Keown, 'Euthanasia, Ethics and Public Policy' (2003) Medical Law Review 11, 256.

61 Sunday Times 20 August 2017.

${ }^{62}$ Team decisions in hospital settings seem to have a cloak of authority: R Rhodes 'Physicians, Assisted Suicide and the right to live or die' in M Battin, R Rhodes, A Silvers (eds) Physician Assisted Suicide (NY, Routledge, 1998).

${ }^{63}$ D Orentlichter, 'The Supreme Court and terminal sedation' in M Battin, R Rhodes, A Silvers (eds) Physician Assisted Suicide (NY, Routledge,1998).

${ }^{64}$ E Jackson, 'Whose Death is it Anyway? Euthanasia and the Medical Profession' (2004) CLP 415, 436. Indeed, it seems that neither opoids nor sedatives need shorten life: N Sykes and A Thorns, 'The Use of Opioids and Sedatives at the End of Life' (2003) 4 Lancet Oncology 312, 317. So its foundations in medicine seem fallacious, as well as morally and legally dubious: See for example, G Williams, Intention and Causation in medical nonkilling: the impact of criminal law concepts on euthanasia and assisted suicide (Routledge, London, 2007) ch 2.
} 
espoused by the CPS. Yet not only is a blind eye turned to cases of 'double effect' because medical professionals who assist suicide risk prosecution, it is positively encouraged even by those who oppose assisted suicide and who oppose the exercise of discretion. ${ }^{65}$

\section{Towards a 'Freedom-Based' AVD Policy}

\section{The Foundations of the Policy}

We have seen that the current policy is weak with respect to all three core values. Consequently the freedom of victims is unnecessarily constrained in several ways: many suicides are made unnecessarily distressing; many suicides take place away from family and friends; many assisted deaths are pushed underground, making voluntariness harder to assess. And the freedom of perpetrators is also unnecessarily constrained, putting many of those who genuinely seek to help carry out the wishes of victims at risk of prosecution, and subjecting them to intrusive investigations. It is true that there are very few prosecutions. But that does not mean that few perpetrators are at risk. For example, medical professionals who openly gave substantial assistance would probably be prosecuted, as would organisers of UK-Dignitas and people who sold DIY-suicide death kits. This policy bans initiatives like these that might make the final days of suicidal people easier. If any of the effects that the current policy leads to starvation, exile to Dignitas, the agony of an overdose, the dismay and pain following a failed suicide attempt, clandestine killing on the pretext of 'double effect' - were forced on one person by another it would be criminal and/or a violation of Art 3 of the ECHR. It is surely 'inhuman and degrading treatment'. This is what is forced onto countless numbers of people who are already suffering beyond endurance.

What would a policy that conformed to the 'freedom' model and its core values look like? First, the consultation would be with the general public, the medical professions, and subsets of people with disabilities, chronic conditions and terminal illness. It would explain why the autonomy principle (with the two limbs identified in Part II) should be the basis of the policy. It would inform consultees of such facts about assisted death as are known or estimated under different kinds of legal regime. The consultation would seek views on the autonomy principle (and compare those of the sets of consultees) and consult on how to articulate that principle. It would consult on the key elements identified in this paper: how to best give effect to genuinely autonomous wishes to die; the (limited) ways in which the motivation of, and

\footnotetext{
${ }^{65}$ For a leading example see J Keown, Euthanasia, Ethics and Public Policy (Cambridge, CUP, 2002).
} 
degree of assistance given by, perpetrators are relevant; and how to protect people who may be at risk of being pressured into suicide.

Second, we need to be realistic about 'autonomy'. The idea that individuals have completely free choices, made in isolation from outside influences, is - like the free market a myth. There is a spectrum of choice in all things, from complete freedom of choice to coercion masquerading as choice. In the middle of the spectrum lies the problem of people making choices that they would not make in other circumstances, including making choices that they think others want them to make (whether under pressure or not). 'Autonomy' is not exercised in a vacuum.

Most people therefore make choices of their own free will but rarely in conditions of their own choosing. This is as true of people considering AVD as it is of people considering other choices in life. This is a structured matter, in AVD as elsewhere. George argues that the structural position of women in western society places more pressure on them to choose to die than it does on men: 'For some women, assisted death might not demonstrate their autonomy, but their acquiescence to controlling influences. ${ }^{66} \mathrm{We}$ might note the similarly powerful, but different, impact of social class: wealth, for example, widens one's choices greatly. But while we should acknowledge the inadequacy of all conceptions of individual autonomy, it follows that if it is inadequate to the task of driving policy about the types of life/death decisions discussed here, it is similarly inadequate to drive other equally important policies - for example, religious choice, education, and going to war. Like democracy, the concept of individual autonomy should be replaced by a better alternative, but as there is no better alternative we must make the best of it. That includes being vigilant about individual autonomy becoming overwhelmed by the influence of others, and doing what we can about the conditions that distort choice. We therefore need to create the system that best identifies and encourages non-lethal solutions for people who ask to die.

Third, a change of policy will change the climate around AVD. Attitudes, followed by the law and practice, could slide down a slippery slope towards greater acceptance of suicide. This could increase social pressure on the weak, ill and vulnerable to end their lives prematurely. This will make the encouraging of non-lethal solutions all the more important. As Herring observes, 'The central legal message we should be sending out to people wishing to commit suicide is 'please don't'.' He rightly states that the law and public health system should

\footnotetext{
${ }^{66} \mathrm{~K}$ George, 'A woman's choice? The gendered risks of voluntary euthanasia and physician-assisted suicide' (2007) Medical Law Review 1, 29.
} 
be aligned to offer 'care, comfort and support' ${ }^{67}$ (ie, doing what we can about the conditions that distort choice). Thus the value of human life needs to be placed alongside that of autonomy as the foundation of a new policy. But this is as much a matter of the quality of life as its existence. Adequate palliative care is often unavailable, often ineffective and often inappropriate (eg where pain is not the problem). ${ }^{68}$ The principles of valuing human life and autonomy necessarily co-exist. For in a liberal society it is as impermissible to tell someone who wishes to die that s/he cannot, as it is to tell someone who does not want to die that $\mathrm{s} / \mathrm{he}$ should do so (and it is even more impermissible to have laws that give effect, directly or indirectly, to such commands). The role of law is not to adjudicate between these principles but to ensure they both have space to operate in as unfettered a way as possible. Policy on AVD should therefore be a matter of both criminal justice and public health. ${ }^{69}$

Keown argues that since autonomy amounts to a right to die and to be killed, this would be incompatible with the 'right to life' in Art 2 ECHR. ${ }^{70}$ But as Coggan observes, living and dying are not opposites. They are processes that co-exist: the process of dying arguably begins at the start of life, and certainly proceeds by middle age. People who demand control over the process by which they die are asserting control over how they live the final part of their life. Thus the argument of, for example, Greasley, that death is a denial of personal autonomy (since no choices exist to be made following death), and that therefore personal autonomy cannot provide a justification for the legalisation of AVD, is also flawed. ${ }^{71}$

Further, there is no reason why one should not have the right to (apparently) opposite things. For example, 'Having the right to consent to treatment does not render the right to refuse treatment as useless. Consenting to a sterilisation does not stand the Convention on its head, even though it can obviate the exercise of the right to found a family under Article 12. ${ }^{72}$ So, those who are against allowing AVD because they fear the downgrading of certain lives should have no cause for concern, as long as it is regulated in ways that signal the value of everyone's

\footnotetext{
${ }^{67}$ Herring, n 22.

${ }^{68}$ See eg S Carr, P Beresford, T Coldham (eds), Assisted dying: developing the debate (2017) (www.shapingourlives.org.uk/).

${ }^{69}$ Drawing on Coggan, 'Assisted dying and the context of debate: 'medical law'versus 'end-of-life law' (2010) Medical Law Review 541, 549.

70 J Keown, 'European Court of Human Rights: Death in Strasbourg-assisted suicide, the Pretty case, and the European Convention on Human Rights' (2003) 1 International Journal of Constitutional Law 722-730.

${ }^{71} \mathrm{~K}$ Greasley, 'R (Purdy) v DPP and the case for wilful blindness' (2010) OJLS 30, 301. The same is true of her argument, and others like it, that $\mathrm{AD}$ cannot generally be in the interests of the 'victim' because it cannot be better to be dead than alive (she admits of some exceptions here, but they are not central to the argument). Even if this argument were acceptable in principle, it would only work if one has a choice in the matter. But we don't. We all die eventually.

72 J Coggan, 'Could the right to die with dignity represent a new right to die in English law?' (2006) Medical Law Review 14, 219.
} 
life. The right to life of every person should be seen as underlined, not undermined, by a right to die. ${ }^{73}$

Showing one policy to be less than wholly effective is of limited value unless one can show that another is or would be more effective. The 'dark figure' of illegal killing discussed earlier varies across different regimes. For example, a survey of 3,000 Australian doctors found non-voluntary euthanasia to be five times more common in Australia, where VE is illegal, than it is in the Netherlands, where it is legal. Further, Australian doctors were far less likely than their Dutch counterparts to discuss the decision to hasten a patient's death with the patient herself, or to seek her consent. ${ }^{74}$ Evaluations suggest that criminalising VE is less effective in controlling non-voluntary euthanasia than policies like that of the Netherlands. ${ }^{75}$

If there is a danger of a permissive AVD regime creating a climate of active life-ending, there is an equally high risk of a restrictive AVD regime creating a climate of deception concerning the procuring and administering of drugs, the drugs paper trail, and post-mortem paperwork. $^{76}$ In such a climate, not only is AVD tolerated among many health care professionals, but wrong-doing is far less likely to be discovered than in jurisdictions where AVD is allowed in regulated circumstances. So even in the Netherlands, there is deception: AVD by relatives is not permitted, but many doctors are aware of it, occasionally facilitate it, and often report such deaths as 'natural'. The deception is not primarily a product of Netherlands' permissiveness, but of the ban on relative-assisted dying. ${ }^{77}$ In the UK this is exacerbated by the cover for euthanasia provided by 'double effect'.

\section{The need for pre-death regulation: A three stage approach}

A new pre-death system for regulating AVD is needed, whether operated by health care professionals, judicial figures, or another body. The sole criterion should be a voluntary, informed, clear and settled wish to die. But this is not the sole requirement.

A pre-requisite - the first stage - would be better social and palliative care so that all realistic alternatives to death are explored and offered before people decide to take this final

\footnotetext{
73 The idea of a 'right to die' is not, readers will not be surprised to discover, straightforward. To keep the discussion manageable, this paper will not (and does not need to) tackle that problem; see Coggan ibid and J Finnis, 'A British 'Convention right' to assistance in suicide?' (2015) LQR 1 for different discussions.

${ }^{74} \mathrm{H}$ Kuhse, P Singer, P Baume, M Clark, and M Rickard, 'End-of-Life Decisions in Australian Medical Practice' (1997) 166 Medical Journal of Australia 191-6.

${ }^{75}$ H. Biggs, Euthanasia, Death with Dignity and the Law, (Hart, 2001); M Freeman, 'Denying Death its Dominion: Thoughts on the Dianne Pretty Case' (2002) 10 Medical Law Review 245; E Jackson, n 70, p 431.

${ }^{76}$ Magnusson, n 59.

77 S Ost and A Mullock, 'Pushing the Boundaries of Lawful Assisted Dying in the Netherlands? Existential Suffering and Lay Assistance’ (2011) EJ Health Law 163, 180 (citing Dutch research by Chabot).
} 
step. Take Greasley's objection to an autonomy-based policy. It would allow assisted dying for extreme examples such as teenagers who feel life is not worth living in the absence of their one true love. In Greasley's opinion, the only way of controlling this is to interpose an objective valuation of that stated belief. In deciding that the teenager is unreasonable but others (people objectively suffering hugely such as Tony Nicklinson) are reasonable we are valuing some lives above those of others. ${ }^{78}$ This is why some disability-rights groups oppose the legalisation of AVD. ${ }^{79}$ However, if the only requirement is a voluntary, informed and settled expressed wish to die, no objective evaluation of the value of other peoples' lives is needed. Nonetheless, the younger the person (and anyone under 18 would be subject to 'best interests' principles anyway) and the less objectively rational the wish, the less likely it is to be informed and settled'. This would justify more extensive enquiry and a longer period of reflection than would be needed for, for example, the terminally ill. The issue is not that those lives are of different value but that those people are differentially able to settle on the most important decision of their lives. Ultimately, though, it eventually becomes each individual's sole decision. That is why 'compromise' positions, relying as they do on an element of objective valuation of life, ${ }^{80}$ are either incoherent or offensive.

Greasley's underlying concern here is with a 'slippery slope'. Similarly, Ost observes that 'a potential danger of loosening the medical criteria for assisted death is that it becomes harder to identify and maintain boundaries'. ${ }^{81}$ But boundaries to what prompts the wish to die cannot be constructed. Kay Gilderdale's 31 year-old daughter, Lynn, was neither terminally ill nor as terribly immobilised as Daniel James or Tony Nicklinson. Yet Kay helped Lynn to die because Lynn's suffering for nearly 20 years from ME led her to attempt suicide several times. ${ }^{82}$ Edward Downes, aged 85 and suffering from great pain, deafness and blindness, decided to die with his wife, who was terminally ill. He could have continued to live, but did not wish to. ${ }^{83}$ In the Netherlands a woman in her twenties, who had suffered sexual abuse from the age of five to 15 , suffered so badly from post-traumatic-stress disorder (severe anorexia,

\footnotetext{
${ }^{78} \mathrm{~K}$ Greasley, n 78, p 301.

79 See L Carr 'Legalising assisted dying is dangerous for disabled people. Not compassionate' (Guardian, 9 September 2016).

${ }^{80}$ For example, R Heywood and A Mullock ('The value of life in English law: revered but not sacred?' (2016) 36 Legal Studies 658) side with Greasley in the matter of the lovelorn teenager. For another advocacy of compromise see R Huxtable, Euthanasia, Ethics and the Law (Routledge, 2007).

81 S Ost, 'The de-medicalisation of assisted dying: is a less medicalised model the way forward?' Medical Law Review (2010) 497, 526.

${ }^{82}$ Guardian, 25 January 2010.

${ }^{83}$ Observer $19 / 7 / 2009$.
} 
chronic depression and hallucinations) that doctors believed she could not be cured; consequently, she requested VE, which was granted. ${ }^{84}$

There is no doubt that the wish to die of all these people was voluntary, informed and settled. Who are we to decide whether they were 'right', and - if we decide they were not - to deny their wishes? Even the most principled objectors to AVD, such as was Bishop Desmond Tutu, sometimes change their views when confronted with a painful and/or distressing decline in their quality of life. ${ }^{85}$

Greasley's argument illustrates another problem for those using 'slippery slope' arguments against legalising assisted dying. They work, if they work at all, both ways. Greasley says that 'the law would not regard the assisted dying of a depressed, lovesick teenager as beyond recrimination ... because the teenager, though she might not know it, has everything to live for. ${ }^{86}$ But if the reason for objecting to someone helping such a person to die is the objective fact that she has much to live for, it is not the assistance that is the problem. It is her wish to die that is the problem. If we think that people with objective reasons to live should not be helped to die then we should also think they should not be allowed to take their own lives. This argument against legalising AVD is a logical slippery slope leading to the recriminalisation of suicide. If we resist the logic of this 'upward' move we should equally resist the logic of the posited 'downward' move.

The second stage would be the establishment of a pre-death regulatory system operated by people involved in social and medical care, and authorised accordingly. A 'conscience clause' would enable people to opt out of authorising AVD, allowing those seeking AVD to find someone who has no such concerns. This kind of transparent system would reduce both the abuse and the well-motivated but 'dark' practices currently carried out by relatives and medical professionals alike. The precise form of this system would be appropriate for public consultation on the lines set out in section II.

The third stage concerns VE. The irony of the current AS policy is that, because of the way it de facto decriminalises much AS whilst maintaining the probability of prosecution of much other AS, it pushes many people into committing VE. So if the current restrictive policy towards AS is continued, a similar approach (de facto partial decriminalisation) should be adopted for VE. This logic would not necessarily apply if a new system following the two stages outlined above were adopted. If everyone who sought AVD were allowed AS, following

\footnotetext{
${ }^{84}$ Independent, 11 May 2016.

${ }^{85}$ Guardian, 7 October 2016.

${ }^{86} \mathrm{~N} 78, \mathrm{p} 321$.
} 
the kind of counselling and support described above, VE need only be sought in two circumstances:

a) individuals who wish to die but not to kill themselves: one way of looking at this is to say that reluctance to carry out the final act indicates that the wish to die is not definitively settled. However, this is surely an empirical matter. Arguably, a requirement that the 'victim' carry out the final act would be a safeguard against abuse. But if such a system is flawed - and what systems are not? - people could still be pressured into AS. And while 'autonomy' undoubtedly requires that people be allowed to seek and find help to die, it does not necessarily require that people be allowed to kill others. These are finely balanced arguments. It is precisely in such circumstances that public consultation has a role, if done as set out in section II.

b) Individuals who cannot kill themselves except by starvation: this is what Tony Nicklinson had to do to exercise his one last act of autonomy, a way of death in violation of Art 3 ECHR. In Nicklinson it was suggested that an eye-movement controlled machine that could administer lethal drugs would be a solution in such cases. It would not, of course, be a solution currently, as the supplier would undoubtedly be prosecuted. ${ }^{87}$ But the freedom-based approach advocated here would allow this solution. Until then, and until such machines can be made both effective and freely available, VE should be treated in the same way as AS for this category of people. Even then, there will remain arguments for VE as set out in a) above, on which there should be public consultation.

\section{Conclusion}

Canada's ban on AS was recently challenged in the Supreme Court of Canada. The court decided that this ban was contrary to Canada's Charter of Rights and Freedoms. It gave the government of Canada twelve months to draft a law allowing doctor-assisted suicide. It also recognised the link between AS and VE, deciding that a new AVD policy had to cover both. ${ }^{88}$

\footnotetext{
${ }^{87}$ Remember, the police recently raided the home of someone planning to use a 'euthanasia kit' to end her own life: $\mathrm{n} 47$.

${ }^{88}$ Carter v Canada [2015] 1 SCR 331. For discussion see, for example, B Chan and M Somerville, 'Converting the 'right to life' to the 'right to physician-assisted suicide and euthanasia': an analysis of Carter $v$ Canada' Medical Law Review (2016) 143.
} 
In Nicklinson the UK Supreme Court viewed the UK's AS policy as similarly incompatible with human rights. It warned that if Parliament does not deal with the problem, the courts may have to. Parliament did subsequently consider the issue but it rejected the Falconer Bill. ${ }^{89}$ This Bill was, in any event, deeply flawed: catering only for the terminally ill, it would not have helped either Mrs Purdy or Mr Nicklinson, and we have seen that any objective criterion for AVD is unacceptable.

At least 12 different jurisdictions (counting 6 US States separately) now allow some forms of AS and/or VE. Two Australian States are currently legalising AVD, and 20 more US States are actively considering it. ${ }^{90}$ The South African judiciary is drifting in this direction. ${ }^{91}$ The UK is becoming out of line with other democracies, ${ }^{92}$ so if a freedom-based approach to AVD were introduced this would be unexceptional.

The current CPS policy is a sticking plaster that completely fails on all three core values of criminal justice. We have seen that it could be improved, but it will always fail badly. We have an ageing population, many members of which suffer medical problems that would have been terminal not long ago. Keeping people alive in difficult conditions is wonderful for those who wish to continue to live, but harrowing for those who do not. This problem will only increase. It is currently addressed by post-death assessment by non-medical institutions and by clandestine medical killing under the guise of palliative care. This is what happens when society turns a blind eye (such as Greasly commends to us) instead of confronting the problem head-on. Regulating AVD pre-death will not not a complete solution to our collective failure to tackle end-of-life problems. But it is a necessary part of it, and a great advance on the current approach.

\footnotetext{
${ }^{89}$ Whether this now settles the matter, as far as judicial development of the law is concerned, is a matter of ongoing dispute in Conway (Guardian, 31 March 2017).

90 For a good overview of developments in several jurisdictions, see J Downie, 'Permitting voluntary euthanasia and assisted suicide: law reform pathways for common law jurisdictions' (2016) QUT Law Review 16, 84; also see Guardian 20/9/2017 on the Bill in Victoria.

${ }^{91}$ D McQouid-Mason, 'Stransham-Ford v. Minister of Justice and Correctional Services and Others: Can active voluntary euthanasia and doctor-assisted suicide be legally justified?' (2015) South African Journal of Bioethics and Law 8, 34.

${ }^{92}$ Conway [2017] EWHC 2447 (Admin) is the latest refusal to listen to those who seek help to die, in a judgement that put 'sanctity of human life' at its centre; and which, as an aside, denied the existence of nonvoluntary medical euthanasia that is evidenced in Section IV [para 124].
} 